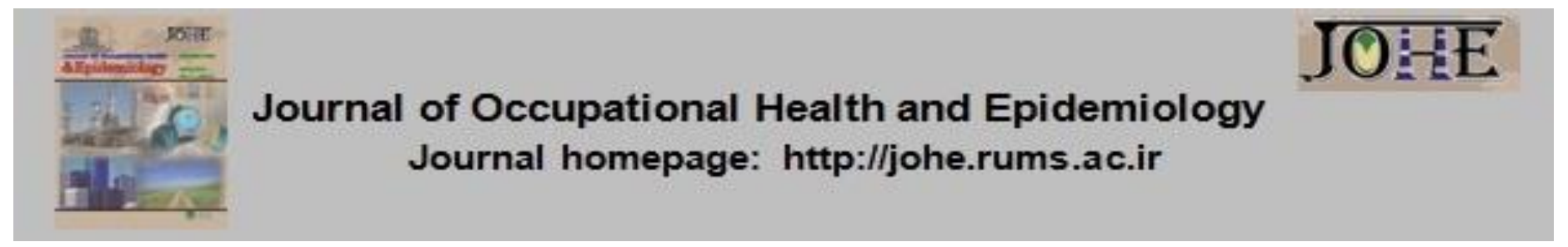

\title{
Selection of internal safety auditors in an Indian construction organization based on the SWARA and ARAS methods
}

\author{
Raja Prasad ${ }^{1 *}$ \\ - Sr. Associate Prof., National Institute of Construction Management and Research (NICMAR), Hyderabad, Telangana, India.
}

Article Info

* Corresponding author:

Raja Prasad,

E-mail:

sunku.vsrp@gmail.com

\section{Article history}

Received: Mar, 2019

Accepted: Aug, 2019

10.29252/johe.8.3.134

Print ISSN: 2251-8096 Online ISSN: 2252-0902

Peer review under responsibility of Journal of Occupational Health and Epidemiology
Citation: Prasad R. Selection of internal safety auditors in an Indian construction organization based on the SWARA and ARAS methods. JOHE 2019; 8(3):134-40.

\begin{abstract}
Background: The effectiveness and adequacy of occupational health and safety management system should be monitored and evaluated at organization level on a regular basis. Safety audit has a clear role in the development of organizations safety management systems. Internal safety audit is a method to appraise to the management the current status of occupational health and safety at workplace. Selection of internal safety auditors is a crucial decision making process which depend on several criteria. The purpose of the study was to select internal auditors among the safety officers in a construction organization using step-wise weight assessment ratio analysis (SWARA) and additive ratio assessment (ARAS) method.

Materials and Methods: The study is based on the subjective evaluation of performance criteria by decision makers and 19 safety officers eligible to conduct safety audit were considered. Finally, six safety officers were considered for the position of internal safety auditors. The SWARA method was applied to calculate weights for criteria of selection and ARAS method was adopted to rank the safety officers.

Results: Seven criteria were considered as per the requirement of the organization and calculated the weights. The overall performance index was calculated based on criteria weights to rank the safety officers.

Conclusions: The findings of this study showed that the SWARA and ARAS methods are useful to select the internal safety auditors. The analysis is simple and can be adopted in practical in situations where the number of criteria varies.
\end{abstract}

Keywords: Safety Management, Occupational Health, Safety Culture, Management Audit, Risk

\section{Introduction}

Safety audit is a systematic, objective and documented evaluation of the occupational safety and health systems and procedures. To fulfil the requirements of safety audit, Indian standard has been developed which establishes audit objectives, criteria and practices, and provides guidelines for establishing, planning, conducting and documenting of audits on occupational health and safety (OHS) systems at workplace. The standard also provides guidelines for verifying the existence and implementation of elements of $\mathrm{OHS}$ system and for verifying the system's ability to achieve defined OHS objectives. The safety audits are of two types, external and internal. External audits are those carried out by agencies external to the auditee organization. Internal audits are conducted by the employees designated by the management. Internal auditors may be selected among employees, preferably from amongst not having direct responsibility in the areas being audited nor having responsibility for implementation of recommendations. It is desirable that organizations have a combination of external and internal OHS audit system. While the external audit in respect of organizations may be conducted 
once in two years, or as specified by any statute, the frequency of internal audit may be set once in every year. Records of accidents and dangerous occurrences should be examined and used to identify high risk areas and activities and consequently the frequency of internal audit may be increased [1].

The design and focus of internal audit has a profound impact on safety culture and bottom line results. An internal safety audit program is not effective in isolation. In well-run companies it is a critical component of the plan- do-check-actbusiness improvement process and an essential element of the overall management system. The minimum expectation for any operationally excellent organization is to meet or exceed all of its compliance obligations/requirements in the jurisdictions in which it operates [2]. An internal auditing program is an investment and while the benefits of the investment are often not clearly visible. The internal health and safety audit methodology provides guidance to auditors and auditees on the internal health and safety audit process. The internal audit methodology ensures that Occupational Health and Safety Management System (OHSMS) audits are conducted to a consistent standard, allowing verification that the OHSMS complies with planned arrangements; has been properly implemented and maintained; and is effectively implemented [3]. The auditor's expertise in the field of health and safety is important when the company's compliance with legal requirements is evaluated [4]. An exploratory was conducted in European process industries to ascertain the facts and opinions on the internal auditing of process safety. The barriers for successful auditing was believed to be lack of senior management commitment, lack of auditor competence, sites are over audited, audit is too shallow and no budget to resolve findings [5].

Safety audit, which is a detailed examination and evaluation of all components of the system to ensure that they comply with prescribed standards. Safety auditing is important to measure the level of safety at the construction site. After the auditing session, the safety officer may know the level of safety at the construction site whether it meets the safety standard requirement or not. The effective implementation of safety audits in Malaysian construction sites practices is possible through commitment of top management and the allocation of resources [6]. The audit of work place conditions in polish construction enterprises is exercised more often with the assistance of site management and persons involved in the development of work safety [7]. Organizations are now considering audits as a real manner to improve; in order to reach higher levels in the maturing process of its management system [8]. Internal safety audit should avoid duplication of effort and focus on those areas that add the most value through an analysis of existing governance programs.

The role of internal safety audits is to audit the efficacy of the safety management system itself and associated critical controls, the high consequence compliance obligations, and the efficacy of important corrective and preventive actions. The selection of internal safety auditors is a crucial decision making process and depend on several criteria. The study aims to establish an effective multi criteria decision making (MCDM) model for internal safety auditor's selection in a Indian construction organization. The purpose of the study is to strenghthen the internal audit system so that management can perceive the status of safety performance of the organization. MCDM model based on the Step-wise Weight Assessment Ratio Analysis (SWARA) for determining weights of evaluation criteria, and on the Additive ratio assessment (ARAS) method for ranking alternatives, in this case ranking of internal safety auditors in the selection process.

\section{Materials and Methods}

MCDM techniques provide decision makers with a tool in order to enable them to advance in solving multi-criteria decision problem, where several conflicting criteria are taken into account. There is no single MCDM method which can be superior method for all decision-making problems [9]. So long as qualitative (ordinal) and quantitative (cardinal) data are handled appropriately, the ranking of decision options is unlikely to change [10]. MCDM methods use criteria weights in the process of analysis. These weights to criteria play an important role for measuring overall preferences of alternatives. The weighing methods are the subjective weighting based on the preferences of the decision-makers and in the objective weighting, the weights are obtained by mathematical methods and decision makers have no role in determining the relative importance of criteria. In the current study the MCDM techniques, SWARA and ARAS are adopted which are based on the subjective judgement of experts in the domain of safety audit.

The Step-wise Weight Assessment Ratio Analysis (SWARA) technique was proposed by Kersuliene et al. (2010) [11]. The SWARA is a newly proposed method; it is used for solving many problems such as: the design of products [12], a machine tool selection [13]. The process of determining the relative weights of criteria using SWARA method 
can accurately be shown by using the following steps:

Step 1: The criteria are sorted in descending order based on their expected significances.

Step 2: The respondent expresses the relative importance of criterion $j$ in relation to the previous (j-1) criterion, for each particular criterion. According to Kersuliene et al. (2010), this ratio is called the Comparative importance of average value, sj.

Step 3: Determine the coefficient kj as follows;

$$
k j=1 \text { for } j=1 ; k j=s j+1 \text { for } j>1
$$

Step 4: Determine the recalculated weight qj as follows;

$$
\text { qj }=1 \text { for } j=1 ; q j=k j-1 / k j \text { for } j>1
$$

Step 5: The relative weights of the evaluation criteria are determined as follows;

$$
w j=q j / \sum_{k=1}^{n} q k
$$

A new additive ratio assessment (ARAS) method was proposed by Zavadskas and Turskis (2010) [14].Therefore the ARAS method can be classified as a newly formed, but effective and easy to use. The ARAS method has been applied to solve various decision making problems. The procedure of solving problems by using ARAS methods can be precisely described by using the following steps:

Step 1: Determine optimal performance rating for each criterion.

After creating a decision matrix, the next step in the ARAS method is to determine the optimal performance rating for each criterion. If decision makers do not have preferences, the optimal performance ratings are calculated as:

$$
\mathrm{x} 0 \mathrm{j}=\max \mathrm{xij}
$$

Step 2: Calculate the normalized decision matrix $\mathrm{R}$ $=$ [rij]. The normalized performance ratings are calculated by using the following formula:

$$
r i j=x_{i=0}^{m} / \sum x i j
$$

Where rij is normalized performance rating of $i$-th alternative in relation to the $\mathrm{j}$-th criterion.

Step 3: Calculate the weighted normalized decision matrix $\mathrm{V}=$ [vij]. The weighted normalized performance ratings are calculated by using the following formula:

$$
\text { vij }=\text { wj . rij }
$$

Where vij is weighted normalized performance rating of $\mathrm{i}$-th alternative in relation to the $\mathrm{j}$-th criterion.

Step 4: Calculate the overall performance index for each alternative. The overall performance index $\mathrm{Si}$, for each alternative, can be calculated as the sum of weighted normalized performance ratings, using the following formula:

$$
\underset{j=1}{\mathrm{Si}=\sum \text { vij }}
$$

Step 5: Calculate the degree of utility for each alternative. The degree of utility function value determines the relative efficiency of an alternative over the best alternative. The degree of utility can be calculated by using the formula.

$$
\mathrm{Qi}=\mathrm{Si} / \mathrm{SO}
$$

Where Qi is degree of utility of i-th alternative, and SO is overall performance index of optimal alternative, and it is usually 1 .

Step 6: Rank alternatives and/or select the most efficient one. The considered alternatives are ranked by ascending Qi, i.e. the alternatives with greater values of Qi have a higher priority (rank) and the alternative with the largest value of $Q i$ is the best placed.

A major construction organization involved in execution of various infrastructure and real estate projects across India desired to develop internal safety audit system so as to improve safety performance. The organization has established a safety department comprising of corporate safety head, 30 safety managers and 75 safety officers to implement and monitor safety performance at project level. The management has decided to strengthen the internal audit system, by selecting internal auditors among the safety officers of the organization. The proposed internal audit wing consists of two safety officers as internal safety auditors. The internal auditor's role is to conduct safety audit as per the schedule communicated and to submit the report to the corporate safety head along with recommendations.

The safety department was forwarded a circular to all the safety officers mentioning the required criteria to perform the role of internal safety auditors of the organization. In response to the circular, 19 safety officers were shown willingness to work as internal safety auditors and also submitted their credentials. A committee was constituted comprising of safety head, independent safety consultant and an academician in the domain of construction safety to select the internal auditors. The committee has shortlisted six safety officers after detailed discussion and two internal safety auditors are to be selected among six eligible candidates. The final selection of internal safety auditors was carried out by adopting SWARA and ARAS methods. The opinions of the committee are vital in determining the criteria weights and subsequent analysis.

One of the fundamental requirements for an OHSMS is planning and conducting audits as part 
of a comprehensive internal audit program. An important component of an effective audit program is ensuring the competence of the individuals who plan and conduct the audits; which includes the auditors and audit team leaders. Confidence in the results of an audit is often heavily dependent on confidence in the competency of those who conduct the audit [15]. The evaluation of individual auditor competence needs to be planned, implemented and documented in accordance with the audit procedures established by an organization. It is the responsibility of the organization to determine that the competence of a particular individual meets the criteria based on its needs and applicable legal and other requirements. An audit is a systematic, independent and documented process for obtaining audit evidence and evaluating it objectively to determine the extent to which the audit criteria are fulfilled. Auditors are expected to be independent from the functions they are auditing in order to maintain impartiality and objectivity. Ensuring that this independence is maintained throughout the audit process is important to ensuring the credibility of the audit findings.

It is not necessary for each auditor in an audit team to have the same level of competence; however, the overall competence of the audit team needs to be sufficient to achieve the objectives established for the audit. When an audit is conducted by a single person, the auditor needs to possess the knowledge and skills needed to complete all aspects of the audit. In order to conduct management system audits, each auditor must possess both audit process related knowledge and skills and discipline-specific (i.e.
OHS) knowledge and skills. In addition, auditors must possess organizational knowledge/philosophy applicable to the specific organization being audited. This organizationspecific information would include knowledge about an organization's business and management practices, an understanding of the types of hazards and nature of risks related to the activities being audited and an understanding of relevant legal and contractual requirements $[1,16,17]$.

Based on the limited literature available on the criteria for selection of internal auditors and based on the opinions of safety consultants, safety managers and academicians in the domain of OHS; the author of the manuscript proposes the following evaluating criteria in the process of selection of internal safety auditor among safety officers of the construction organization. Evaluation criteria are shown in Table 1.

Table 1: Evaluation Criteria for internal safety auditors

\begin{tabular}{ll}
\hline \multicolumn{1}{c}{ Criteria } & Symbol \\
\hline Qualification and experience & $\mathrm{QE}$ \\
\hline Identifying root causes & $\mathrm{IR}$ \\
\hline Independence and objectivity & $\mathrm{IO}$ \\
\hline Communication skills & $\mathrm{CS}$ \\
\hline Understanding organization needs & $\mathrm{UO}$ \\
\hline Analytical skills & $\mathrm{AS}$ \\
\hline Dependable & $\mathrm{DL}$ \\
\hline
\end{tabular}

\section{Results}

The SWARA method was applied to calculate weights for criteria and ARAS was adopted to rank the safety officers for the position of internal safety auditors. The opinions of the committee were considered for analysis. The opinion of the expert 1 , as well as calculated weight of the criteria is shown in Table 2.

Table 2: Calculated weights based on the opinion of Expert 1

\begin{tabular}{|c|c|c|c|c|}
\hline Criteria & sj & kj & qj & $\mathbf{w j}$ \\
\hline Qualification and experience & & 1 & 1 & 0.273 \\
\hline Identifying root causes & 0.16 & 1.16 & 0.862 & 0.236 \\
\hline Independence and objectivity & 0.10 & 1.10 & 0.784 & 0.214 \\
\hline Communication skills & 0.32 & 1.32 & 0.594 & 0.162 \\
\hline Understanding organization needs & 1.22 & 2.22 & 0.268 & 0.073 \\
\hline Analytical skills & 1.46 & 2.46 & 0.109 & 0.030 \\
\hline Dependable & 1.62 & 2.62 & 0.042 & 0.012 \\
\hline
\end{tabular}

The values in the column sj represent the attitudes of expert, i.e. values given by experts. The values in columns $\mathrm{kj}$, qj and wj obtained using Equations (1), (2) and (3). Similarly based on the opinions experts 2 and 3 , the weights for criteria were calculated and the expert wise weights and overall weights of the criteria is shown in Table 3 . The overall criteria weight is calculated geometric mean of weights obtained from the experts. 
Table 3: Overall criteria weight

\begin{tabular}{lcccc}
\multicolumn{1}{c}{ Criteria } & $\begin{array}{c}\text { Weight } \\
\text { (expert 1) }\end{array}$ & $\begin{array}{c}\text { Weight } \\
\text { (expert 2) }\end{array}$ & $\begin{array}{c}\text { Weight } \\
\text { (expert 3) }\end{array}$ & $\begin{array}{c}\text { Overall } \\
\text { weight, wj }\end{array}$ \\
\hline Qualification and experience & 0.273 & 0.312 & 0.277 & 0.287 \\
\hline Identifying root causes & 0.236 & 0.214 & 0.200 & 0.216 \\
\hline Independence and objectivity & 0.214 & 0.196 & 0.202 & 0.204 \\
\hline Communication skills & 0.162 & 0.158 & 0.152 & 0.157 \\
\hline Understanding organization needs & 0.073 & 0.091 & 0.085 & 0.083 \\
\hline Analytical skills & 0.030 & 0.020 & 0.048 & 0.034 \\
\hline Dependable & 0.012 & 0.009 & 0.036 & 0.019 \\
\hline
\end{tabular}

In the next step, ARAS method was applied to rank the safety officers. The ratings of six safety officers on 1-5 scale, obtained from three experts. The rating of the expert 1 is shown in Table 4.

Table 4: Ratings of Expert 1

\begin{tabular}{cccccccc}
\hline & QE & IR & IO & CS & UO & AS & DL \\
\hline S1 & 4 & 4 & 3 & 5 & 3 & 4 & 4 \\
\hline S2 & 3 & 5 & 4 & 3 & 4 & 3 & 5 \\
\hline S3 & 2 & 4 & 5 & 4 & 5 & 5 & 4 \\
\hline S4 & 5 & 3 & 4 & 3 & 4 & 4 & 3 \\
\hline S5 & 4 & 4 & 4 & 5 & 5 & 5 & 2 \\
\hline S6 & 5 & 5 & 4 & 4 & 4 & 4 & 2 \\
\hline
\end{tabular}

Similarly ratings were obtained from expert 2 and 3 . The overall ratings of evaluated candidates are determined as geometric mean of ratings obtained from experts. Table 5 shows the weights of evaluation criteria. The optimal performance ratings, in row S0, obtained using Eq. (4).

Table 5: Average ratings

\begin{tabular}{llllllll}
\hline & QE & IR & IO & CS & UO & AS & DL \\
\hline S1 & 4.00 & 4.64 & 3.92 & 3.30 & 4.23 & 4.00 & 4.23 \\
\hline S2 & 3.92 & 5.00 & 4.23 & 3.92 & 3.42 & 4.00 & 4.64 \\
\hline S3 & 3.42 & 4.00 & 4.31 & 3.42 & 3.92 & 4.31 & 4.31 \\
\hline S4 & 4.31 & 4.23 & 4.64 & 3.30 & 3.30 & 3.92 & 4.00 \\
\hline S5 & 3.30 & 4.64 & 3.92 & 3.42 & 3.00 & 3.92 & 3.92 \\
\hline S6 & 4.64 & 4.31 & 4.00 & 3.00 & 3.92 & 4.00 & 4.00 \\
\hline S0 & 4.64 & 5.00 & 4.64 & 3.92 & 4.23 & 4.31 & 4.64 \\
\hline
\end{tabular}

The normal and weighted normalized ratings were weighted normalized ratings are shown in Table 6 . determined by using the Equations (5) and (6). The

Table 6: Weighted normalized ratings

\begin{tabular}{cccccccc}
\hline & QE & IR & IO & CS & UO & AS & DL \\
\hline wj & 0.287 & 0.216 & 0.204 & 0.157 & 0.083 & 0.034 & 0.019 \\
\hline S1 & 0.142 & 0.146 & 0.132 & 0.136 & 0.163 & 0.140 & 0.142 \\
\hline S2 & 0.139 & 0.157 & 0.143 & 0.161 & 0.131 & 0.140 & 0.156 \\
\hline S3 & 0.121 & 0.126 & 0.145 & 0.141 & 0.151 & 0.151 & 0.145 \\
\hline S4 & 0.153 & 0.133 & 0.156 & 0.136 & 0.127 & 0.138 & 0.134 \\
\hline S5 & 0.117 & 0.146 & 0.132 & 0.141 & 0.115 & 0.138 & 0.132 \\
\hline S6 & 0.164 & 0.135 & 0.135 & 0.124 & 0.151 & 0.140 & 0.134 \\
\hline S0 & 0.164 & 0.157 & 0.156 & 0.161 & 0.163 & 0.151 & 0.151 \\
\hline
\end{tabular}

The overall performance indexe and degrees of utility, obtained by using the Equations (7) and (8), are shown in Table 7.

Final results from Table 7 indicate that the safety officers S2 and S4 have the highest total importance, and therefore considered for the positions of internal safety auditors of the organization.
Table 7: Ranking of internal safety auditors

\begin{tabular}{lccc}
\hline & Si & Qi & Rank \\
\hline S0 & 0.160 & & \\
\hline S1 & 0.143 & 0.890 & 4 \\
\hline S2 & 0.146 & 0.913 & 1 \\
\hline S3 & 0.135 & 0.844 & 5 \\
\hline S4 & 0.145 & 0.906 & 2 \\
\hline S5 & 0.132 & 0.825 & 6 \\
\hline S6 & 0.144 & 0.900 & 3 \\
\hline
\end{tabular}




\section{Discussion}

The current study was conducted to select the internal safety auditors from the eligible safety officers in a Indian construction organization. As illustrated in Table 1, seven criteria were considered for selection process of internal safety auditors. The criteria was finalized after conducting brainstorming session with the management of the construction organization and experts in the domain of safety audit.

The SWARA method was applied to calculate weights for criteria and ARAS was adopted to rank the safety officers for the position of internal safety auditors.A three member committee was constituted to evaluate the weights of the criteria based on their subjective judgements. The weights of the criteria based on the judgement of expert 1 was presented in Table 2. Simlarly the weights of criteria based on opinion of expert $2 \& 3$ and the overall weights are presented in Table 3 . The overall weight of the criteria; "qualification and experience (0.287)", "identifying root causes $(0.216)$ " and "independence and objectivity $(0.204)$ " are more important in the selection process of internal safety auditors; while the weight of "dependable (0.019)" is the lowest among the seven criteria.

A study was conducted to rank the banks based on their performance in Serbia by considering five banks and four criteria by adopting multi criteria decision making techniques such as ARAS, the multi-objective optimization by ratio analysis, complex proportional assessment and simple additive weighting. The results of the study indicate that there is a certain similarity in results obtained by using these methods [18]. A study was conducted to select a pile column technology by considering five alternatives and six criteria; and analysed by adopting the techniques ARAS, technique for order preference by similarity to ideal solution (TOPSIS) and complex proportional assessment (COPRAS). The results of the study show that the ranking of technology is exactly same in all the three methods [19]. ARAS method was adopted in project selection in telecommunication sector by considering five alternatives and four criteria [20].

ARAS method was applied to rank the safety officers by obtaining the ratings of experts on 1-5 scale as shown in Table 4. The average ratings and normalized ratings are presented in Table 5 and Table 6 respectively. Data from Table 7 indicate that the safety officer labeled as S2 (0.913) and S4 (0.906) have the highest total importance, and therefore has best results in terms of evaluated criteria.
Selection of internal safety auditors is a significant task in the field of safety management, and it has a critical role to play in improving the safety performance of any organization, regardless of the type of industry. In this study, a brief review of the literature was provided, and several competencies were identified from the existing competency frameworks. Obviously, given the existence of multiple aspects of competency, the internal auditor selection involves a multi criteria problem, which should be answered by using MCDM methods. Decision maker's preferences are put into decision process as criteria weights and then a simple weighted summation technique is adopted separately for the criteria. An overall performance index and degree of utility of the alternatives is taken into account while ranking the alternatives.

\section{Conclusion}

The selection of safety officers as internal safety auditors is a multi criteria making process involving several criteria and the results of SWARA-ARAS methods can successfully resolve problems in terms of selection. The model can be adopted in any scenario of selection process by adding or deleting the criteria as per requirements of the organization. As a direction of future research, the model can be validated by applying on situations involving multi criteria making process and solved by other techniques.

\section{Acknowledgement}

The author is grateful to all the safety experts who cooperated with me in this research. The author would like to thank the reviewers for their feedback and constructive criticism of an earlier version. Any limitations and shortcomings of the work remain the responsibility of the author.

Conflict of interest: None declared.

\section{References}

1. Indian Standard. Code of Practice on Occupational Safety and Health Audit. New Delhi: Bureau of Indian Standards; 1998. 16 p. Report No.: 14489. Available from: https://ia801602.us.archive.org/3/items/gov.law.i s.14489.1998/is.14489.1998.pdf

2. Wolfe J, Brun J. Internal Audit Best Practices for Environment, Safety, Risk, and Quality. Montreal, Canada: Nimonik Inc: cited 2019. 19 p. Report No.: 1-888-608-7511.

3. Robson LS, Clarke JA, Cullen K, Bielecky A, Severin C, Bigelow PhL, et al. The effectiveness of occupational health and safety management system interventions: A systematic review. Saf Sci 2007; 45(3):329-53. 
4. Kuusisto A. Safety management systems Audit tools and Reliability of auditing [PhD thesis]. Tampere, Finland, Tampere University of Technology; 2001.

5. Allford L. Internal Auditing of Process Safety. Chem Eng Trans 2016; 53: 313-18.

6. Keng TCh, Razak N. Case Studies on the Safety Management at Construction Site. Journal of Sustainability Science and Management 2014; 9(2):90-108.

7. Gardziota T. A New Work Safety Management System in Construction Sites. Organization and Management 2014; 62:21-30.

8. Escobar Rivera D, Simon Villar A, Salzar Marrero Jl. Auditors Selection and Audit Team Formation in Integrated Audits. Quality Access to Success 2017; 18(157):65-71.

9. Abrishamchi A, Ebrahimian A, Tajrishi M, Marino MA. Case study: Application of Multicriteria Decision Making to Urban Water Supply. J Water Resour Plan Manag 2005; 131(4):326-35.

10. Hajkowicz S. Higgins, A. A comparison of multiple criteria analysis techniques for water resource management. Eur J Oper Res 2008; 184(1):255-65.

11. Kersuliene V, Zavadskas EK, Turskis Z. Selection of rational dispute resolution method by applying new step - wise weight assessment ratio analysis (SWARA). Journal of Business Economics and Management 2010; 11(2): 24358.

12. Zolfani SH, Zavadskas EK, Turskis Z. Design of Products with Both International and Local Perspectives based on Yin-Yang Balance Theory and SWARA Method. Journal of Economic Research 2013; 26(2):153-66.

13. Aghdaie MH, Zolfani SH, Zavadskas EK.
Decision making in machine tool selection: An integrated approach with SWARA and COPRAS-G methods. Economics of Engineering 2013; 24(1): 5-17.

14. Zavadskas EK, Turskis Z. A new additive ratio assessment (ARAS) method in multicriteria decision-making. Ukio Technological and Economic Development 2010; 16(2): 159-72.

15. Baybutt P. Competency requirements for process safety auditors. Process Safety Progress 2015; 34(2):179-82.

16. International Organization for Standardization. Guidelines for Auditing Management Systems. Geneva Switzerland: International Organization for Standardization; 2018 Jul. 46 p. Report No.: $19011 . \quad$ Available from: https://www.iso.org/standard/70017.html

17. Shahadat $H$, Salam KMA. Basic Approach of an Electrical Safety Assessment in RMG Industries: Development of Electrical Hazards. Paper presented at: The 10th Global Engineering, Science and Technology Conference; 2015 Jan 2-3; Dhaka, Bangladesh.

18. Stanujkic D, Đordević B, Đordević M. Comparative Analysis of Some Prominent MCDM Methods: A Case of Ranking Serbian Banks. Serbian Journal of Management 2013; 8(2):213-41.

19. Zavadskas EK, Sušinskas $S$, Daniūnas A, Turskis Z, Sivilevičius H. Multiple criteria selection of pile-column construction technology. Journal of Civil Engineering and Management 2012; 18(6):834-42.

20. Bakshi T, Sarkar B. MCA Based Performance Evaluation of Project Selection. International Journal of Software Engineering \& Applications 2011; 2(2):14-22. 